\title{
UM RAIO-X DA ELITE CHARQUEADORA PELOTENSE DO SÉCULO XIX
}

\author{
An X-ray of the 19th century Pelotas City elite
}

Daniel de Souza Lemos ${ }^{1}$

\begin{abstract}
RESUMO
Resenha da obra Os Barões do Charque e suas fortunas. Um estudo sobre as elites regionais brasileiras a partir de uma análise dos charqueadores de Pelotas (Rio Grande do Sul, século XIX), do historiador Jonas Vargas. Palavras-chave: Elite; Charqueadores, Pelotas.
\end{abstract}

\begin{abstract}
Review of the work "The Barões do Charque and their fortunes. A study of Brazilian regional elites from an analysis of the pelletizers in Pelotas city (Rio Grande do Sul, century XIX)", do historian Jonas Vargas.

Keywords: elite, charqueadores, Pelotas
\end{abstract}

VARGAS, Jonas. Os Barões do Charque e suas fortunas. Um estudo sobre as elites regionais brasileiras a partir de uma análise dos charqueadores de Pelotas (Rio Grande do Sul, século XIX). São Leopoldo: Oikos, 2016.

"As principais famílias charqueadoras do período escravista foram capazes de criar um mundo próprio e fizeram da cidade de Pelotas o seu palco particular. Neste cenário, o acesso às artes, à 
educação superior e à liderança política coube a elas e a algumas outras famílias da elite local” (Vargas, 2016, p.317)

O cantor e compositor Vitor Ramil, certa feita, disse ter "convicção que o Rio Grande do Sul não estava à margem do centro do Brasil, mas sim no centro de uma outra história". Ramil, que é pelotense, certamente formulou essa opinião tendo como inspiração a sua amada cidade natal, que a retrata de modo idealista, ou realista, como Satolep. Pois essa Pelotas centro de uma outra história é a encontrada no profundo trabalho escrito pelo historiador e professor do curso de História da UFPel, Jonas Vargas.

O livro "Os Barões do Charque e suas fortunas. Um estudo sobre as elites regionais brasileiras a partir de uma análise dos charqueadores de Pelotas (Rio Grande do Sul, século XIX)", é uma adaptação da sua tese de doutoramento em História, defendida na Universidade Federal do Rio de Janeiro, em 2013. Nesta obra, Vargas faz um exaustivo estudo sobre a elite pelotense, e demonstra que Ramil está correto em sua reflexão estética: Pelotas é o centro de uma outra história.

No decorrer de sete capítulos, Vargas apresenta mais de cem anos de história. Desde a "montagem do complexo charqueador escravista" (no capítulo 1), que ocorre entre 1780- 1835 até o melhor momento da elite pelotense, quando esta se constitui no que o autor chama de "aristocracia do sebo" (capítulo 7). Ocasião em que é apresentado ao leitor como essa elite exercia o poder político, educava seus filhos e como era seu nobre estilo de vida. Nas palavras de Vargas:

Uma profunda endogamia combinada com uma engenharia matrimonial que estabelecia alianças com genros de outras províncias e até outros países, demonstrava o seu prestígio social local e regional. Pelo estilo de vida que levavam, pela importância dada à educação dos filhos, pelos baronatos e a notabilidade política com que conduziam os negócios da urbe, eram tidos pelos seus próprios pares como a "aristocracia da terra”. (VARGAS, 2016, p.218) 
Esta caracterização demonstra que a cidade se destacava no cenário cultural da província, e confirma a tese da "opulência e da cultura" que Pelotas representava no século XIX. Contudo, a força do estudo de Vargas está no exaustivo acervo documental que visita - inventários post mortem, processos criminais, correspondências particulares, mapas de população, crônicas da época - para endossar sua argumentação.

Muitos estudos já foram feitos sobre a Pelotas do ciclo das charqueadas, no século XIX, e provavelmente todos eles foram citados por Vargas. Muitos nomes que se debruçaram sobre a história das charqueadas, dos negros escravizados e das origens de Pelotas são destacados no decorrer do texto: Fortunato Pimentel (sem data), Auguste Sant-Hilaire (1974), Fernando Henrique Cardoso (1977), Mário Maestri (1984), Mário Osório Magalhães (1993), Eduardo Arriada (1994), Jorge Euzébio Assumpção (1995), Marcos Hallal dos Anjos (1996), Beatriz Loner (1997 e 1999), Ester Gutierrez (2001), Carla Menegat (2009 e 2010), Adão Monquelat (2009 e 2010), Caiuá Al-Alan (21008 e 2011), entre outros. Inclusive, Vargas não se acanha em contestar autores clássicos, como faz com Fernando Henrique Cardoso, por exemplo:

Analisando o trabalho cativo nas charqueadas, Fernando Henrique Cardoso formulou a tese da "economia de desperdício" nestes estabelecimentos. Tal afirmação sustentava-se no fato de que a sefra nas charqueadas durava em torno de 6 a 7 meses (novembro a abril/maio). Inspirado em Louis Couty, Cardoso afirmou que numa empresa capitalista, com o término da matança, os empregados seriam dispensados e recontratados na próxima safra, enquanto que nas charqueadas os senhores eram obrigados a manter o sustento de seus plantéis improdutivos por mais um semestre. Berenice Corsetti e Ester Gutierrez já refutaram esta afirmação, pois havia uma série de atividades para além das charqueadas, em que os escravos podiam ser empregados. Além da charqueada, muitos empresários também possuíam olarias, algo que não era privilégio dos charqueadores mais ricos. (VARGAS, 2016, p.110).

Ainda no primeiro capítulo do livro, o autor apresenta dados estatísticos da época estudada, para afirmar que Pelotas era uma cidade 
negra, pelo menos na primeira metade do século XIX. Pois, em 1814, $50,7 \%$ da população da então freguesia de São Francisco de Paula era constituída de trabalhadores negros escravizados. Posteriormente, em 1833 esta população contava com 5.623 negros enquanto os brancos representavam 3.933 indivíduos.

No segundo capítulo do livro, Vargas trata da estratificação socioeconômica e a imigração estrangeira durante o auge e a decadência do ciclo charqueador, ocorrido entre os anos 1850 e 1890. A fonte utilizada nessa tarefa foram os 302 inventários da camada mais rica da população pelotense, cujos processos se encontram no Arquivo Público do Estado do Rio Grande do Sul.

É nesta parte do trabalho que o autor explica o processo de branqueamento da população urbana da cidade de Pelotas. Conforme informa o historiador, o fim tráfico de escravos em 1850, e o ingresso de imigrantes europeus foram os fatos que contribuíram para que ocorresse o aumento da população branca. Em suas palavras "Pelotas havia se tornado uma das inúmeras localidades das Américas que receberam europeus em seu território" (VARGAS, 2016, p.74)

Sobre o perfil dos imigrantes, Vargas consultou os passaportes policiais emitidos para os europeus que entraram na cidade, que constam armazenados no Arquivo Público do Estado do Rio Grande do Sul. Nos passaportes estão registrados: nacionalidade, local de procedência, profissão, idade e estado civil do estrangeiro. A maioria veio de Portugal, 59\% dos imigrantes listados. Eram caixeiros, alfaiates, chapeleiros, sapateiros, mascates, comerciantes e uma série de profissionais despossuídos de riqueza material. Além dos portugueses, alemães, italianos, franceses, uruguaios espanhóis e ingleses chegaram a Pelotas, no período.

O propósito da elite pelotense com o estímulo à entrada de imigrantes europeus, Vargas resume assim:

Passado mais de meio século, sua pretensiosa elite buscou fazer dela uma cidade "européia". Neste duplo movimento, ela jamais deixou de ser uma cidade atlântica, recebendo um número de migrantes forçados e voluntários, das mais diversas regiões da Europa, da América e da África, desde o início de sua história. As transformações ocorridas no mundo atlântico oitocentista podiam ser observadas nas próprias ruas da cidade, perante uma diversidade de línguas, de cores, de culturas. Era sobre essa base 
social extensa e complexa que os charqueadores ocupavam o topo da hierarquia socioeconômica local. (VARGAS, 2016, p.93)

Como funciona, afinal, uma charqueada? Como é o dia a dia da atividade do trabalhador negro escravizado? A maneira como é feita a divisão social do trabalho, a distribuição das tarefas e o papel produtivo de negro são detalhadamente apresentados, e analisados, no terceiro capítulo do livro. Em "as unidades produtivas, o mundo do trabalho nas charqueadas, a administração dos cativos e o tráfico interprovincial de escravos", Vargas leva o leitor para dentro de uma charqueada pelotense.

Conforme o historiador, os processos-crime relativos aos conflitos ocorridos no interior das charqueadas são as melhores fontes para desvendar esse universo insalubre que estava situado nas margens dos rios São Gonçalo e Pelotas e que possuía os seguintes utensílios: barraca de couros, galpão de charquear, graxeira, mangueira, senzala, forno de secar sal, varais de charque e caldeiras.

Quanto ao processo de produção do charque, Vargas retira dos seguintes viajantes que testemunharam a atividade: Nicolau Dreys, (em 1839), Louis Couty (em 1880) e Herbert Smith (em 1882). Este, inclusive, é mencionado no início da introdução dos "Barões do Charque" (página 11), pelo autor, para descrever deliciosamente a cena horrenda e típica dos verões pelotenses, na região de produção do charque

A partir da página 96, Vargas começa a descrever "minuciosamente" as etapas da atividade: a) o abate; b) da esfolação ao charqueamento; c) do salgamento ao secamento nos varais; e d) o tratamento dos subprodutos, bem como a graxa, o couro, o sebo e outros. Apenas quatro passos, que por um lado causavam repugnância aos estrangeiros e, por outro, a fortuna dos charqueadores.

A bandeira vermelha na entrada das charqueadas era o sinal de que ao longo do verão cerca de 300 a 400 mil rezes seriam abatidas. Função esta que reunia comerciantes, caixeiros, peões, tropeiros, capatazes e escravos durante a safra. A prática que foi aperfeiçoada com o tempo permitia o abate diário de 600 a 700 rezes, em uma unidade produtiva. Os escravos exerciam funções variadas, e alguns eram experts em determinados ofícios ligados à produção, como, por exemplo, carneadores, salgadores, graxeiros, serventes, tripeiros, descarnadores e sebeiros. 
Numa atuação mais ampliada do trabalhador escravizado, contudo, Vargas destaca uma série de outros ofícios, quais sejam: campeiros, marinheiros, artesãos, carpinteiros, alfaiates, sapateiros, pedreiros, tanoeiros, lombilheiros, marceneiros, oleiros, correeiros e ferreiros. As mulheres eram costureiras. Além dessas tarefas, os escravos também eram utilizados no serviço doméstico da casa do charqueador.

Nos capítulos quatro e cinco Vargas problematiza o aspecto econômico do charque, ou seja, os mercados em que o produto é comercializado, onde os charqueadores-empresários fazem a sua fortuna. Além de tratar do papel da guerra na manutenção da rentabilidade do negócio, que tinha no charque platino o grande concorrente. E, a pressão que a elite charqueadora pelotense fazia junto a corte no sentido de buscar uma proteção para a atividade econômica.

De acordo com Vargas:

Se ela não conseguiu impor uma política protecionista ao charque para conter a concorrência platina, foi capaz de insuflar o Império para envolver-se em três guerras, às quais ela ajudou a bancar financeiramente e que lhe deram uma sobrevida naquele ramo de negócios. (VARGAS, 2016, p.318).

No capítulo 6 "Os barões do charque: perfil e níveis de riqueza, mobilidade social intraelite e transmissão de patrimônio"; E, no capítulo 7 "A aristocracia do sebo: poder político nobreza, educação e estilo de vida nas famílias da elite charqueadora", o autor utiliza o método prosopográfico para compor o perfil da elite pelotense. Esta, certamente, é uma das originalidades do trabalho de Vargas. Pois lhe permitiu trazer uma grande inovação na historiografia sobre o tema relativo a Pelotas, e chegar a seguinte conclusão sobre o grupo estudado:

Quando se analisa quem controlava os principais cargos políticos, os títulos de nobreza e os diplomas de bacharéis, verifica-se que os charqueadores formavam o grupo mais proeminente, reunindo poder, riqueza e status social. Tal fenômeno social conferia um sentimento de superioridade a elas, o que se refletia no seu estilo de vida, nos casamentos e na sua política sucessória. (VARGAS, 2016, p.319) 
Pelo que foi apresentado nesta resenha, o autor de "Os Barões do Charque" trouxe uma profunda contribuição ao assunto. Visitou historiadores locais e também os nacionais e internacionais que trataram da questão da escravidão. Porém, chama a atenção uma ausência, o historiador marxista Jacob Gorender, cujo Escravismo Colonial não apareceu mesmo que para ser criticado. No entanto, alguns seguidores dele foram amplamente citados no livro, a saber, Mário Maestri e Ester Gutierrez.

Esta ausência, entretanto, não tira o brilho do trabalho que, inclusive, mereceu uma menção honrosa no concurso de teses de Doutorado (2013/2014) promovido pela ANPUH Nacional. A Associação Nacional dos Profissionais de História faz jus à qualidade da obra, que trouxe grande contribuição à historiografia sobre Pelotas, às charqueadas e ao trabalho escravo. Portanto, "Os Barões do Charque" merece ser lido, e a presente resenha espera ter estimulado a curiosidade sobre ele.

RECEBIDO EM: 04/03/2020 APROVADO EM: 24/09/2020 